\section{THE FALLS OF NIAGARA AND ITS WATER-POWER.}

$\mathrm{T}^{\circ}$

$O$ render the vast energy of the Niagara Falls available for use in the industrial world has been the dream of many an enterprising spirit who has watched the immense volume of water plunging over the precipice, only to expend its energy in transforming itself (or its equivalent) into an invisible vapour, to be carried by the winds over to the lakes supplying the Falls, and pass through the same cycle again. But till quite recently little has been attempted. For many years past a few mills on the eastern cliff of the Niagara Gorge, below the Falls, have used a certain amount of the power, now aggregating about 6000 horse-power, by conducting water from the river above the Falls through a canal, and using it to drive turbines placed so as to benefit from only 90 to 100 feet or less of the total fall available, the water discharging down the side of the gorge after it has done its work. In this way it may be said that a start has been made, but it is only within the last few years that the utilisation of the power has been undertaken in a bold spirit, and this has become possible by the recent developments in electrical science, which enable power to be transmitted to a distance economically on a commercial basis.

To ensure success the enterprise had to be taken up on an extensive scale by a powerful company. Such a company is the Niagara Falls Power Company, who have been granted franchises for the utilisation of some of the water-power available. The company owns lands covering an area of 1500 acres on the "American" side, and extending along the upper river front for over two miles, on which they propose to develop a large manufacturing centre, but one of an entirely new order-one without the abominations of smoke and concomitant dirt, now so intimately associated with centres of the kind. An allied company has built a whole village on the lands of the Power Company; another has constructed railways to place the various factories in communication with the main lines of railway in the immediate neighbourhood; and others, again, have been formed to deal with the distribution of the power to all the cities and towns coming within the sphere of operations-a rather elastic term when dealing with high pressure electrical distribution. But although it is now more than three years since the Cataract Construction Company-the company formed for carrying out the engineering portion of the immense scheme projected by the Niagara Falls Power Company-commenced their operations, many in this country seem to be quite unaware that a great portion of their work has been already accomplished and the rest is in an advanced state, and of the manner in which the power is to be rendered available for industrial purposes. It is thought that a short description of the works, soon to be in operation, may not be without interest to the readers of NATURE.

That the Niagara Falls are peculiarly well suited to an undertaking of the kind now entered upon is well known. Situated in a comparatively narrow river, connecting Lakes Erie and Untario, and supplied from a vast collecting ground, draining into the huge North American lakes forming the centre--Lake Superior, Lake Michigan, Lake Huron, and Lake Erie-the whole having an area of above 300,000 square miles, or nearly three times the area of Great Britain and Ireland combined, it might be expected that the discharge over the Falls would vary but slightly in volume or height. And such is the case. An estimated quantity of 265,000 cubic feet is precipitated over the Falls each second of time, with but slight variations, all the year round, in winter and summer, whether the river be laden with ice or the foot of the Falls appear choked with frozen spray, and in periods of drought or flood. The ordinary variations in level are not more than I foot above or 5 feet below the Falls, wind in general having the greatest effect on the level of the river. "The greatest authenticated changes of level," says Prof. W. C. Unwin, "below the Falls, due to ice-blocks in the river and other causes, amount to only $13 \frac{1}{2}$ feet rise above mean level and 9 feet fall below it." The drop at the Falls being about 160 feet, or, with the rapids above and immediately below the Falls, 214 feet, within a distance of a mile or a mile and a quarter, it will be seen that the above variations are unimportant; and, in addition, the actual fall to be used for the turbines will be I 40 feet. Further than the above, the level character of the land on the "American" side, adapted for the cutting of canals and erection of factories; the right-angular relative position of the upper and lower

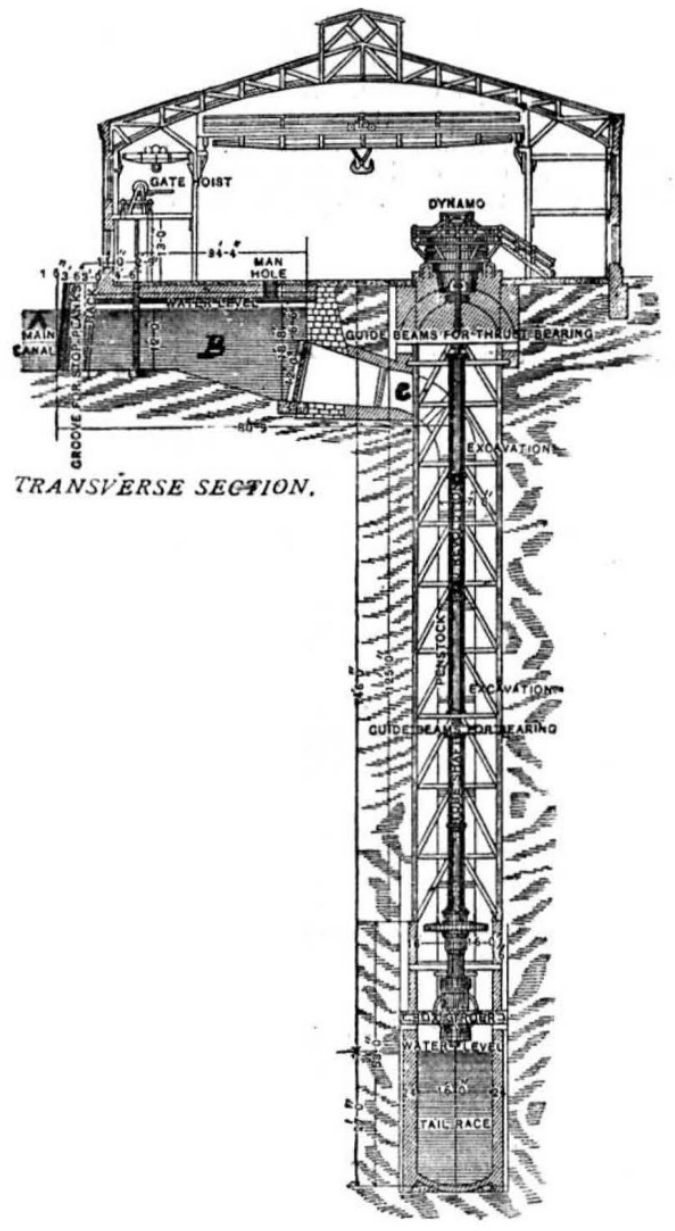

FIG. $x$.

rivers, facilitating the construction of tunnels or tailraces for the disposal of the discharge water from the turbines; and, finally, the abundant means of communication, for the transport of raw materials and manufactured goods, with distant parts, existing in the three or four great lines of railway and the huge chain of navigable lakes in connection with the upper river; all point to the neighbourhood as being one particularly well adapted to the requirements of a power centre for industrial works of the character of that now being formed.

The hydraulic part of the works will be seen, on reference to Fig. I, to consist broadly of a canal, a wheelpit with its turbines, and a tunnel or tail-race. The canal, A, opens out from the upper river, about $I_{2}^{\frac{1}{2}}$ miles above the American Falls, that is, on the north or "American"

NO. I 273 , vOL. 49] 
side, and extends in a north-easterly direction for 1500 feet, with a width of 350 feet, and a depth of 12 feet. At the end of this canal, on the north-west side, are sluicegates controlling the flow of the water into side passages or head-races, $\mathrm{B}$, which conduct the water to the penstocks, c, which guide it from the top of the wheel-pit to the turbines at the bottom. Fig. 2 shows the main canal in course of construction. In the background is seen the Upper Niagara River, flowing from left to right; and in the foreground appear two entrances to one of the head-races. The wheel-pit is nearly 200 feet deep, stone walled, and of sufficient length at present to accommodate three turbines, each of 5000 horse-power, and their penstocks. This will be extended as the demand for power increases. The turbines, which have been made by the I. P. Morris Company, of Philadelphia, from designs by Messrs. Faesch and Piccard, Geneva, Switzerland, are double and of the outward flow shortly to be available, in the continuity of the supply. It is approximately 19 feet wide, and 21 feet high. It is in section in the form of a horse-shoe, and has a mean grade of about 7 per 1000 , and is perfectly straight in a vertical plane. Its length is 7000 feet, or over $1 \frac{1}{4}$ miles. Four courses of hard brick set in cement line the tunnel throughout, the invert being paved with that of the hardest nature-vitrified brick-to resist the wearing action of the stream with its sand and other materials borne along by it. At the mouth of the tunnel the invert and sides are lined with steel plates forming a wave curve, the last few hundred feet sloping more than elsewhere, bringing the lower part of the mouth a few feet under the mean water-level. In this way the water of the river forms a cushion against which the discharge from the tunnel impinges. In Fig. 3 is seen, under the lefthand end of the suspension bridge, the incomplete mouth of the tunnel. In the distance are the American

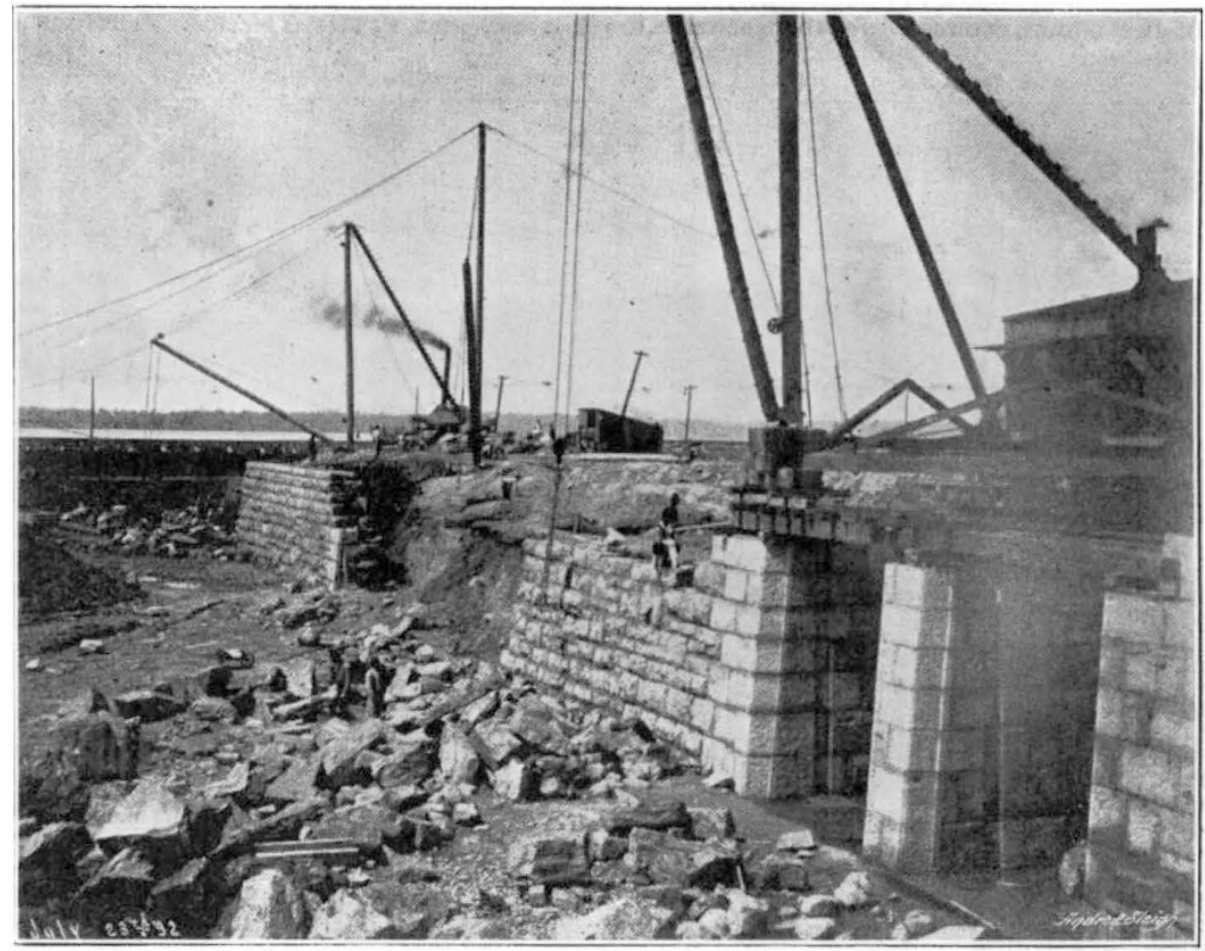

FIG. 2.

type, being placed horizontally, and driving the dynamos for distributing the power, also placed horizontally, in the power-house over the wheel-pit, by means of a long vertical steel shaft, hollow at all parts for the sake of lightness except at the bearings. The turbines and dynamos will revolve at 250 revs. per minute. From the bottom of the wheel-pit a channel leads into the great tunnel, or tail-race, through which the water is discharged into the lower river, a short distance below the upper suspension bridge, after it has passed through the turbines. This tunnel, now completed, is a great work, but only commensurate with the scale on which the whole scheme has been undertaken. It has a capacity sufficient for discharging the water from turbines aggregating about Ioo, 00 h.p., which is the figure towards which the Cataract Construction Company is working at present, and has been constructed with a consideration for durability such as will arrest the confidence of those intending to make use of the power,
Falls, the Horse-shoe Falls being hidden from view The small fraction of the Falls to be diverted for the I00,000 horse-power, represented by the maximum discharge from the tunnel, is forcibly shown by the picture. The regulation of the speed of the turbines will be effected by controlling the flow of water leaving them, by closing the exits from them more or less by means of balanced gates, controlled by governors on the floor of the power-house above.

Passing now from the hydraulic part of the works to the electrical or distributing part, we are presented with one of the most interesting and important developments in electrical engineering practice of the present day.

In the year 1890 the Cataract Construction Company invited selected engineers and engineering firms to consider the problem of distributing the power, and appointed a commission, called the International Niagara Commission, to examine and consider all the projects sent in. It

NO. 1273 , VOL. 49] 
consisted of Lord Kelvin (then Sir William Thomson) as president; Dr. Coleman Sellers, of Philadelphia ; Prof. E. Mascart, Paris; Colonel Theodore Turrettini, Geneva; and Prof. W. Cawthorne Unwin, F.R.S., as secretary. Funds were placed in their hands for the purpose of paying a fixed sum to each competitor sending in a scheme of sufficient importance, and awarding prizes. Meetings of the commissioners were held in London, but no decision was come to as to whether compressed air or electricity should be used-the two means of distributing the power for which schemes were submitted,-and they were not convinced of the superiority of an alternating current over a continuous current system of electrical distribution. Since the commission dissolved, however, a decision was come to in favour of the adoption of electrical distribution, and Prof. George Forbes, F.R.S., being appointed electrical consulting engineer, the outcome has been the adoption of the scheme originally submitted to the commission by him in 1890 and rejected at the time by every one of the commissioners. In that scheme it in the continuous current system to increase the pressure to the figure necessary for economical transmission), and the admirable facility with which the alternating current can be reduced from high to low pressure, and vice versa, for the various requirements-such as electric traction, electro-metallurgy, motive-power and lighting-by that machine which does its work without mechanically moving parts-the alternating current transformer-are strong points in favour of the use of alternating currents. The question of motors is, on the other hand, a strong one, ordinarily, in favour of continuous currents. But when the frequency of the alternating current is low, as is to be the case at Niagara Falls, most of the advantages of continuous current motors over alternating current motors disappear, and the operation of many alternating current motors, already existing, is facilitated.

In regard to the frequency of alternation of the currents. to be adopted at Niagara Falls, we find a very marked departure from existing practice. The frequency hitherto. used has been from 70 to Ioo periods per second in Europe, and 133 in America. There is an exception-

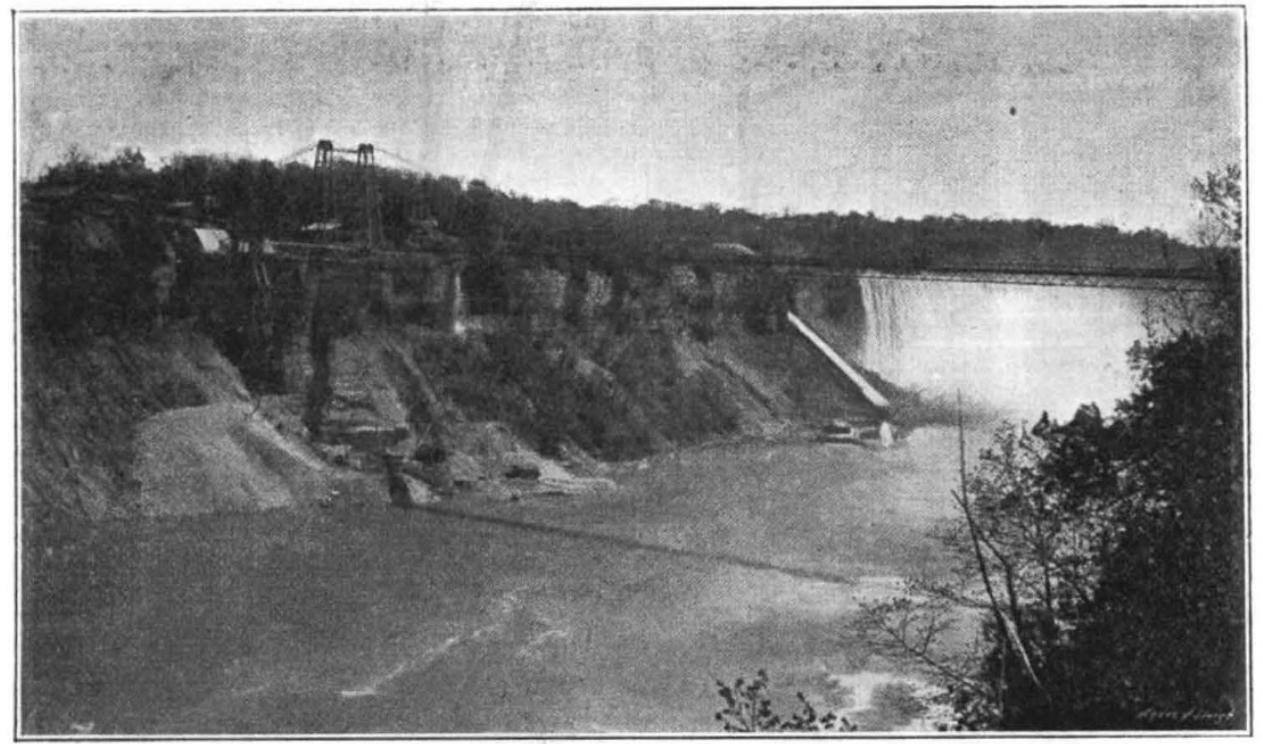

FiG. 3.

was insisted that alternating currents must be used, that the two-phase system should be adopted (that is, one employing two currents which differ from each other with respect to time by 90 degrees or a quarter of a complete period of alternation-when one has a maximum value, positive or negative, the other is a zero, and vice versa), that, using only machinery on the market, 2000 volts should be the pressure for local work, and step-up transformers be employed for raising the pressure for transmission to Buffalo (eighteen miles distant), and that the motors for converting the electrical power into mechanical power at the far ends of the lines should be synchronising motors, Tesla two-phase motors, and motors with commutators and laminated fields. This briefly describes the system to be now adopted; and it is interesting to note the conversion of the commissioners appointed by the Cataract Construction Company, with one notable exception, to viewing with favour the adoption of the alternating current in preference to the continuous current. But the difficulties connected with the insulation of the dynamos from the earth, which is necessary when using a number in series (an arrangement required

NO. I 273 , VOL. 49] that of Messrs. Ganz and Co., of Buda-Pesth-who have adopted 42 periods per second. But the frequency to be used at Niagara Falls will eclipse all, inasmuch as it is to be one of 25 periods per second; and it may be remarked here that one of 16 periods per second would have been adopted, had not the weight of the machine for this periodicity been too heavy for the hydraulic piston (which supports the whole weight of the revolving parts of the turbine and dynamo, and the shaft connecting them, using the head of water driving the turbine, the thrust-bearing shown in Fig. I being merely for preventing motion vertically), using the induction in the iron desired by the manufacturers of the machines, which is lower than that which the Cataract Construction Company's electrical consulting engineer would have preferred.

The advantages to be derived from the use of so low a rate of alternation are many. One has already been mentioned here, namely, the increased number of alternating current motors which become available for use, to which may be added the further great advantage of an improved efficiency in the motors. But probably the greatest advantages of a low frequency are to be found 
in connection with the conductors for the transmission of the power. There are many difficulties experienced with high frequency currents which are either largely mitigated, or entirely removed, by the adoption of a low rate of alternation. There is, first, the tendency of alternating currents to confine themselves to the outside of the conductors carrying them, thereby increasing the resistance, an effect increased by augmenting the frequency; secondly, there is the impedance of the line, due to the magnetic field formed between the go and return wires of a circuit, which is also increased by raising the frequency; another is the tendency to discharge from a conductor, shown so well by Dr. Lodge's experiments with extremely high rates of alternation, which is less marked the lower the frequency; a fourth is that tendency to break down solid insulators, shown by $\mathrm{Mr}$. Tesla, again using currents of extremely high frequency, which is reduced the lower the rate; and lastly there is the loss due to capacity, both owing to static charge, and, combined with the self-induction of the circuit, resonant effects, which is reduced more and more the lower the frequency is made. There is one important objection, in general, to the use of a slow period of alternation, and this is that, with the frequency to be used at Niagara Falls, flickering of lamps, both arc and incandescent, is perceptible. But this objection is very easily overcome by changing the alternating current into a continuous current, as will have to be done for other purposes at Niagara Falls, which may be accomplished in one or two ways, to be mentioned later. This objection, too, had not the same weight at Niagara Falls as it might have at other places, as most of the power transmitted will be used for motive-power purposes.

The electric pressure selected for use in the neighbourhood of Niagara Falls, and for transmission to Buffalo-one of the first more distant places to be supplied with power-will be 2000 volts at first, for the former, and probably 20,000 volts for the latter. As regards the means of obtaining the 20,000 volts, it is much to be regretted that the inability to obtain from American manufacturers a guarantee for machines constructed for such a pressure, they having never supplied machines at a higher pressure than 2000 volts, has necessitated the adoption of step-up transformers. The consequence is that economy has had to give way to expediency, and this has again made itself felt in the pressure of 2000 volts decided upon, as probable, for the local distribution. The use of the extra high pressure, even here, would have obvious advantages. One would be the resulting uniformity in the whole system, local and distant; and a second, the saving to be effected in the amount of copper in the conductors. It is a significant fact in support of this contention that, to put in the most economical section, using 2000 volts, will require $3 \mathrm{sq}$. in. of copper for each conductor, or 12 sq. in. for each 5000 horse-power dynamo.

The dynamos for generating the power in two alternating currents differing in phase by $90^{\circ}$, at $200 \mathrm{~J}$ volts, will be mounted directly on the top of the turbine shafts. They will be of 5000 horse-power each, and were designed specially for the work by Prof. George Forbes, as the Company's electrical consulting engineer, three being now made by the Westinghouse Electric and Manufacturing Company, of Pittsburgh, $\mathrm{Pa}$. In them the armature is fixed, the field magnet, formed of a nickelsteel ring, $12 \mathrm{ft}$. 9 in. in diameter, $4 \mathrm{ft}$. 2 in. high, and 6 in. thick, with the pole-pieces pointing radially inwards, revolving outside. In this way the pole-pieces are well held in against centrifugal force, and, moreover, the magnetic pull between the pole-pieces and armature opposes the centrifugal force of the revolving field magnet. The nickel-steel ring with the pole-pieces is suspended from a steel spider with eight arms, which spreads over the top of the armature like an umbrella, being keyed to the solid steel shat passing through the centre, and attached to the ring by studs and nuts. The attendants will be able to enter the interior of the armature at all times, whether the machine be running or not, for the purpose of attending to the two bearings inside, and the collecting rings on the under side of the spider and the brushes, for passing the current to the exciting coils, \&c.

From the dynamos conductors will be led, in conduits in the floor of the power-house, to a large subway running the whole length of the house and opening into a large cellar underneath it, in which will be placed the transformers for raising the pressure for the transmission of the power outside, and other apparatus.

The means adopted for running the conductors between the power-house and the spots where the power is to be utilised is of the most satisfactory description. Bearing in mind the very real troubles likely to arise with a pole line from lightning, wind, and frost, including the formation of sleet upon the wires and insulators, the Cataract Construction Company abandoned this cheauest form of construction, and decided to build a subway large enough to carry the conductors, and allow of a man walking or travelling on a trolley along the whole length. The length built up to the present extends from the powerhouse to the Pittsburgh Reduction Company's works; to be devoted to the production of aluminium, and one of the first places to be supplied with power, a distance of 2500 feet. This subway, which may eventually be extended to Buffalo, is built after the design of the Cataract Construction Company's electrical consulting engineer, and is of concrete 9 or ro inches in thickness. The height inside is $5 \mathrm{ft}$. $6 \mathrm{in}$. It is of the horse-shoe shape, as shown in Fig. 4, which is from a photograph of the actual work. Iron castings are embedded in the sides every $30 \mathrm{ft}$., on which are bolted brackets carrying oil insulators to carry the bare copper conductors. In front of the conductors, on each side, will be placed screens formed of wooden frames Io ft. long, on which will be stretched open metal, covered with plaster to within about a foot of the top, which will there be left open to allow of inspection of the conductors behind. Down the centre space, 22 inches wide, will be a track for an electric trolley, with a conductor between the rails. Drainage, \&c., has been well provided for, manholes built to the surface of the ground, and each casting carrying insulators is put to earth. The subway will probably be artificially dried by forcing a current of dry air through it. In this way a very satisfactory piece of work, both from the point of view of efficiency, and that of safety, has been undertaken and practically completed, making this part of the work of the same permanent character given to the rest of the undertaking.

It only remains to say a few words with regard to the motors to be used for converting the electrical power into mechanical power at the far ends of the lines, and the other purposes to which it will be put.

For electric lighting the current, as already stated, will have to be transformed into a continuous current on account of the low frequency of alternation adopted; a continuous current will also be required for other purposes, such as street railways, metallurgical works, and probably the working of the canal boats on the Erie Canal running from the Niagara River above the Falls to the Hudson River at Albany, 350 miles distant. This continuous current can be obtained in several ways, one being the well-known method of driving a continuous current dynamo by an alternating current motor; a second by using a commutator, placed where the continuous current is required, and there rotated. With this latter method, besides all the advantages of the alternating current being retained up to the point where the continuous current is required, the rectification can be effected with very inexpensive machinery and without.

NO. I 273 , VOL. 49] 
serious loss. Although no commutator for this special purpose is at present on the market, the solution of the problem has been practically achieved, and may be expected in the immediate future to result in important developments in the electrical distribution of power.

With both the continuous current and the alternating current of low frequency, then, for use at the far end of the lines of suitable pressure, the pressure having been reduced from that on the line wires by transformers, as at the transmitting end it was increased, continuous current motors can be used for power work where most suitable ; the current can be used for electro-metallurgical work and for electric lighting in the ordinary well-known ways, and the alternating current can be used in motors direct, without rectification, everywhere else.

Already a great number of applications for power have been made. As before noted, the Pittsburg Reduction Company has started works for the production of aluminium, and will be supplied with power to the extent

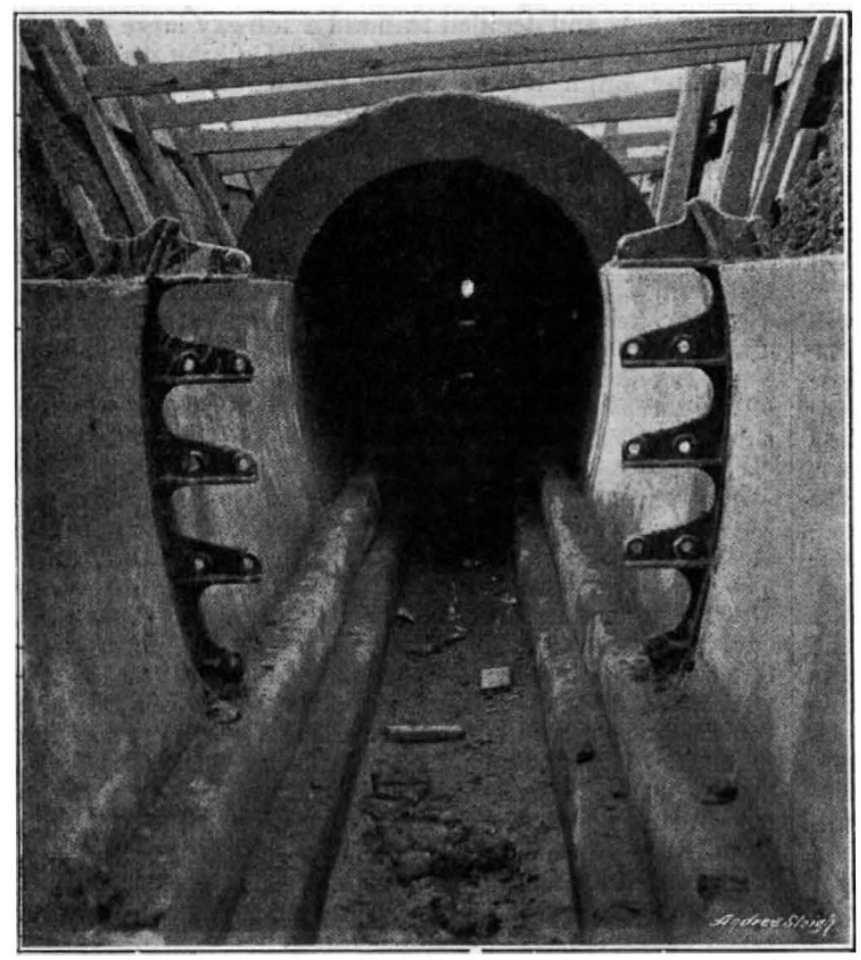

FIG. 4

of, at present, 7000 h.p., at 150 volts. The Niagara Falls Paper Company have erected a mill on the lands of the Power Company, for the making of their wood-pulp, and have sunk their own pit for turbines to the extent of 6000 h.p. The Company will take water from the main canal, and lease the right to use the great tunnel of the Niagara Falls Power Company as a tail-race. This mill, as a power consumer, is representative of a type which will probably use largely the cheap power at the Falls, needing as they do power continuously day and night. Synchronising alternators, as motors, could with effect be used in such cases, hardly ever requiring stopping and starting as they would; and they are of high efficiency. The high pressure might be used in some of these cases, without transforming down, in addition. Applications for power have also been made from Albany, 350 miles from the Falls.

Large as is the extent of the operations described No. I 273 . vol.. 497 above, it is by no means all that is in contemplation, or even being now prosecuted. On the same side of the Falls, rights of way have been obtained for driving a second tunnel, of the same capacity as the first-namely, 100,000 h.p.- -and on the Canadian side powers have also been granted to the Company to use the water-power there, the extent contemplated to which it will be used reaching, it may be, 250,000 h.p. Altogether the total amount for which concessions have been granted amounts to 450,000 h.p., which will involve the abstraction from the Falls of about 12 per cent. of the water. But, large as this may seem at first sight, admirers of the Falls, from the æsthetic point of view, will be glad to hear that it is thought that the diversion of this amount will not be noticeable to visitors to the Falls. And the Niagara Falls Power Company have limited their demands on the side above the American Falls to the 200,000 h.p. It will no doubt be a long time before the full amount for which powers have been obtained will be taken up. What may lie in the future it is impossible to forecast. But, so far, lovers of nature need fear little that they will be deprived of this great work of hers; they will still hear its thunder, be able to watch its ceaseless changing aspects, and revel in the other beauties of this mighty cataract.

\section{NOTES}

THE first (or gentlemen's) soirée of the Royal Society is announced for Wednesday, May 2.

THE Duke of Bedford and Mr. Spencer Pickering, F.R.S., have arranged to start an experimental fruit station, in order to investigate both scientifically and practically the culture of hardy fruits. About twenty acres of land in the neighbourhood of Woburn Abbey have been set apart for the experiments, and the services of an able horticulturist, who will act as local manager, have been secured.

Prof. J. J. Sylvester, F.R.S., has been elected one of the twelve foreign members of the Italian Scientific Academy, founded in $\mathbf{1 7 8 2}$, called "Dei Quaranta." Among the other foreign members of this Academy are Prof. Helmholtz, Lord Kelvin, Prof. Huxley, and M. Pasteur.

DR. J. R. Reynolds, F.R.S., has been re-elected President of the Royal College of Physicians.

THE death is announced of Dr. E. H. Jacob, Professorof Pathology in Yorkshire College, Leeds, at the early age of forty-four.

THE death occurred last week of General Favé, Academicien Libre of the Paris Academy of Sciences, and for a long time head of the Ecole Polytechnique, where he was Professor of Military Art and Fortification.

WE regret to record the death of Mr. W. Pengelly, F.R.S., at Torquay, on Friday last, at the age of eighty-two. He was the author of various papers on geological and other subjects, and his exploration of Kent's Cavern, carried out under the auspices of the British Association, was of extreme importance in establishing the existence of prehistoric man. $\mathrm{He}$ also accumulated and arranged a fine collection of Devonian fossils, which, under the name of the Pengelly Collection, are now in the Oxford University Museum. The President and Committee of the Torquay Natural History Society intend to appeal to the scientific world for funds to build a new lecture-room to their museum, to be called the Pengelly Memorial. Mr. Pengelly 